\title{
Renal Cell Carcinoma Follow-Up - Is it Time to Abandon Ultrasound?
}

\author{
Mark Quinlan ${ }^{\mathrm{a}} \quad$ Gavin Wei $^{\mathrm{a}} \quad$ Niall Davis $^{\mathrm{a}} \quad$ Cedric Poyet $^{\mathrm{a}} \quad$ Marlon Perera $^{\mathrm{a}}$ \\ Damien Bolton $^{\mathrm{a}} \quad$ Nathan Lawrentschuk ${ }^{\mathrm{a}, \mathrm{b}}$ \\ a University of Melbourne, Department of Surgery, Urology Unit, Austin Hospital; ${ }^{\mathrm{b} E}$ J Whitten Prostate Cancer Research Center, \\ Epworth Healthcare, Melbourne, VIC, Australia
}

\author{
Key Words \\ Renal cell cancer • Recurrence • Detection • Ultrasound • \\ Computed tomography $\cdot$ Guidelines
}

\begin{abstract}
Background: We wished to compare the efficacy of ultrasound versus intravenous contrast-enhanced computed tomography (CT) for detecting recurrent renal cell carcinoma (RCC) by identifying patients presenting with such tumor burden and to evaluate the utility of these imaging modalities in these circumstances. Methods: Patients who developed local and/or distant recurrences following surgical intervention for RCC were identified. The imaging regimen utilized during post-operative surveillance was analyzed to determine whether recurrent disease was identifiable on ultrasound or CT or both. Results: Of the 22 patients with recurrent RCC, 16 had previously undergone radical nephrectomy and 6 had undergone partial nephrectomy. Median duration to RCC recurrence was 28.5 months (range 2-66 months). Fourteen patients (64\%) underwent ultrasound during their follow-up surveillance protocol and 1 case of disease recurrence was detected by ultrasound before subsequent confirmation with $C T$. All 22 patients underwent $C T$ as a routine component of their follow-up surveillance protocol and all recurrences were detected by this modality. Six patients had recurrence in their ipsilateral kidney after partial nephrectomy - five had undergone ultrasound in their surveillance protocol and this modality failed to detect a recurrence in
\end{abstract}

\section{KARGER}

Fax +4161306 1234

E-Mail karger@karger.com

www.karger.com
(C) 2019 The Author(s)

Published by S. Karger AG, Basel Upen access

This article is licensed under the Creative Commons AttributionNonCommercial-NoDerivatives 4.0 International License (CC BYNC-ND) (http://www.karger.com/Services/OpenAccessLicense). $\mathrm{NC}-\mathrm{ND}$ ) (http://www.karger.com/Services/OpenAccess License).
Usage and distribution for commercial purposes as well as any distribution of modified material requires written permission. four of these patients. Conclusion: Ultrasound is inferior to CT for detecting recurrent RCC. CT should be recognized as the standard diagnostic modality during post-operative surveillance, in contradiction to what is recommended in many guidelines.

C 2019 The Author(s)

Published by S. Karger AG, Basel

\section{Introduction}

Renal cell carcinoma (RCC) accounts for $2-3 \%$ of all adult malignancies and its incidence is steadily increasing. Approximately $20 \%$ of patients who undergo surgery for localized RCC may develop local and/or distant recurrences [1]. Low volume tumor recurrences may be amenable to salvage local and systemic therapies. Early diagnosis of recurrent RCC is important as 5-year survival for untreated metastatic RCC ranges from just 2.7 to $9 \%[2,3]$. As approximately $50 \%$ of RCC recurrences occur within 2 years post-operatively, a clear rationale exists for optimizing post-operative surveillance strategies $[1,4-6]$. Additionally, this is of importance for early detection of metachronous renal tumors in those patients with papillary or familial RCC [7].

Currently, there is no evidence-based standard for the follow-up of patients with RCC. Specifically, no consensus has been reached on surveillance guidelines after radical $(\mathrm{RN})$ or partial nephrectomy $(\mathrm{PN})$ for $\mathrm{RCC}$.

Mark Quinlan

Department of Urology, Austin Hospital

Heidelberg, Melbourne

VIC 3084 (Australia)

E-Maillynagh@hotmail.com 
Table 1. A selection of some of the guidelines for follow-up post surgical resection of RCC from the EAU, AUA, NCCN and CUA

\begin{tabular}{|c|c|}
\hline Guidelines & Recommendation \\
\hline EAU & Ultrasound at $6 / 12$ and $24 / 12$ for low risk patients. \\
\hline AUA & $\begin{array}{l}\text { - Ultrasound, CT or MRI annually for } 3 \text { years in low risk } \\
\text { patients post PN if initial post-operative scan is negative. } \\
\text { - After initial post-operative CT or MRI, for moderate to } \\
\text { high risk patients, an ultrasound, chest X-ray, CT or MRI } \\
\text { every } 6 / 12 \text { for at least } 3 \text { years and annually thereafter to } \\
\text { year five. } \\
\text { - Ultrasound, chest X-ray, CT or MRI beyond } 5 \text { years may } \\
\text { be performed at the discretion of the clinician for moderate } \\
\text { to high risk patients. }\end{array}$ \\
\hline $\mathrm{NCCN}$ & $\begin{array}{l}\text { For Stage } 2 \text { or } 3 \text { patients after RN, CT or MRI or ultra- } \\
\text { sound every } 3-6 / 12 \text { for at least } 3 \text { years and then annually } \\
\text { up to } 5 \text { years. }\end{array}$ \\
\hline CUA & $\begin{array}{l}\text { For pT2 patients, CT or ultrasound at } 12 / 12,36 / 12 \text { and } \\
60 / 12 \text {. }\end{array}$ \\
\hline
\end{tabular}

The European Association of Urology (EAU), American Urological Association (AUA), National Comprehensive Cancer Network (NCCN) and Canadian Urological Association (CUA) all propose different risk-adapted approaches (table 1) [8-11]. Notably, all of these follow-up guidelines include surveillance with ultrasound and intravenous contrast-enhanced computed tomography (CT) in their recommended protocols. Advantages associated with ultrasound are absence of radiation and low cost. Disadvantages, however, include operator-dependency and suboptimal imaging, particularly in obese patients. No comparative studies have been undertaken to determine whether $\mathrm{CT}$ is superior to ultrasound for detecting recurrent RCC. In the present study, we aim to compare both modalities for detecting recurrent RCC.

\section{Materials and Methods}

All patients who underwent surgical intervention for RCC between January 2009 and May 2017 and who subsequently developed local and/or distant recurrences were identified from our hospital database. Recorded data included patient demographics, date of surgery, type of surgery (RN vs. PN), histological grade and subtype, tumor stage and margin status. In addition, the date and site(s) of disease recurrence as defined by a diagnosis on an imaging modality (ultrasound or CT) were also recorded. Specifically, the imaging regimen utilized during post-operative surveillance was analyzed to determine whether recurrent disease was diagnosed on CT or ultrasound or both. The choice of imaging was made by the individual Consultant or Fellow or Registrar who reviewed the patient during their follow-up.
Table 2. Histological grade, margin status and pathological tumor stage of initial surgery in patients with subsequent recurrent RCC $(n=22)$

\begin{tabular}{lr} 
Histological result & $\mathrm{n}$ \\
\hline Fuhrman Grade 2 & 7 \\
Fuhrman Grade 3 & 11 \\
Fuhrman Grade 4 & 4 \\
Margin negative & 16 \\
Margin positive & 6 \\
pT1 & 5 \\
pT2 & 5 \\
pT3 & 12
\end{tabular}

Table 3. Histopathology, histological subtype and duration to disease recurrence in patients with recurrent $\mathrm{RCC}(\mathrm{n}=22)$

\begin{tabular}{clr}
\hline Patient No. & Histology & $\begin{array}{c}\text { Duration to recurrence } \\
\text { (months) }\end{array}$ \\
\hline $1^{\text {a }}$ & G2pT1R0 clear cell & 64 \\
2 & G2pT2R0 papillary I & 60 \\
3 & G2pT3R0 clear cell & 63 \\
4 & G3pT2R0 acquired cystic & 49 \\
& disease-associated RCC & \\
$5^{\text {a }}$ & G2pT1R0 clear cell & 66 \\
6 & G4pT3R0 clear cell & 12 \\
7 & G3pT3R1 clear cell and papillary I & 10 \\
$8^{\text {a }}$ & G3pT2R0 papillary I & 31 \\
9 & G3pT3R1 clear cell & 27 \\
10 & G3pT3R0 clear cell & 30 \\
11 & G3pT3R0 clear cell & 43 \\
12 & G2pT2R0 clear cell & 7 \\
$13^{\mathrm{a}}$ & G3pT1R1 clear cell & 42 \\
14 & G4pT3R1 clear cell & 5 \\
15 & G3pT3R0 clear cell & 3 \\
16 & G3pT3R0 clear cell & 4 \\
17 & G4pT3R0 clear cell & 8 \\
$18^{\mathrm{a}}$ & G2pT1R0 clear cell & 14 \\
$19^{\mathrm{a}}$ & G3pT1R0 clear cell & 53 \\
20 & G4pT3R1 clear cell & 2 \\
21 & G3pT3R1 clear cell & 19 \\
22 & G2pT2R0 clear cell & 45 \\
\hline & & \\
\hline & & \\
\hline
\end{tabular}

${ }^{\mathrm{a} C}$ Corresponds to patients who underwent PN at initial surgery.

\section{Results}

\section{Patient Demographics}

Twenty-two patients developed recurrent RCC after planned curative surgical intervention, of whom 15 were male. Median age at initial surgery was 65.5 years (range 40-84 years). Sixteen RNs and 6 PNs were initially performed. Histopathologic outcomes are detailed in tables 2 
Table 4. Sites of recurrent RCC and patient specific follow-up protocols with ultrasound and/or CT $(\mathrm{n}=22)$

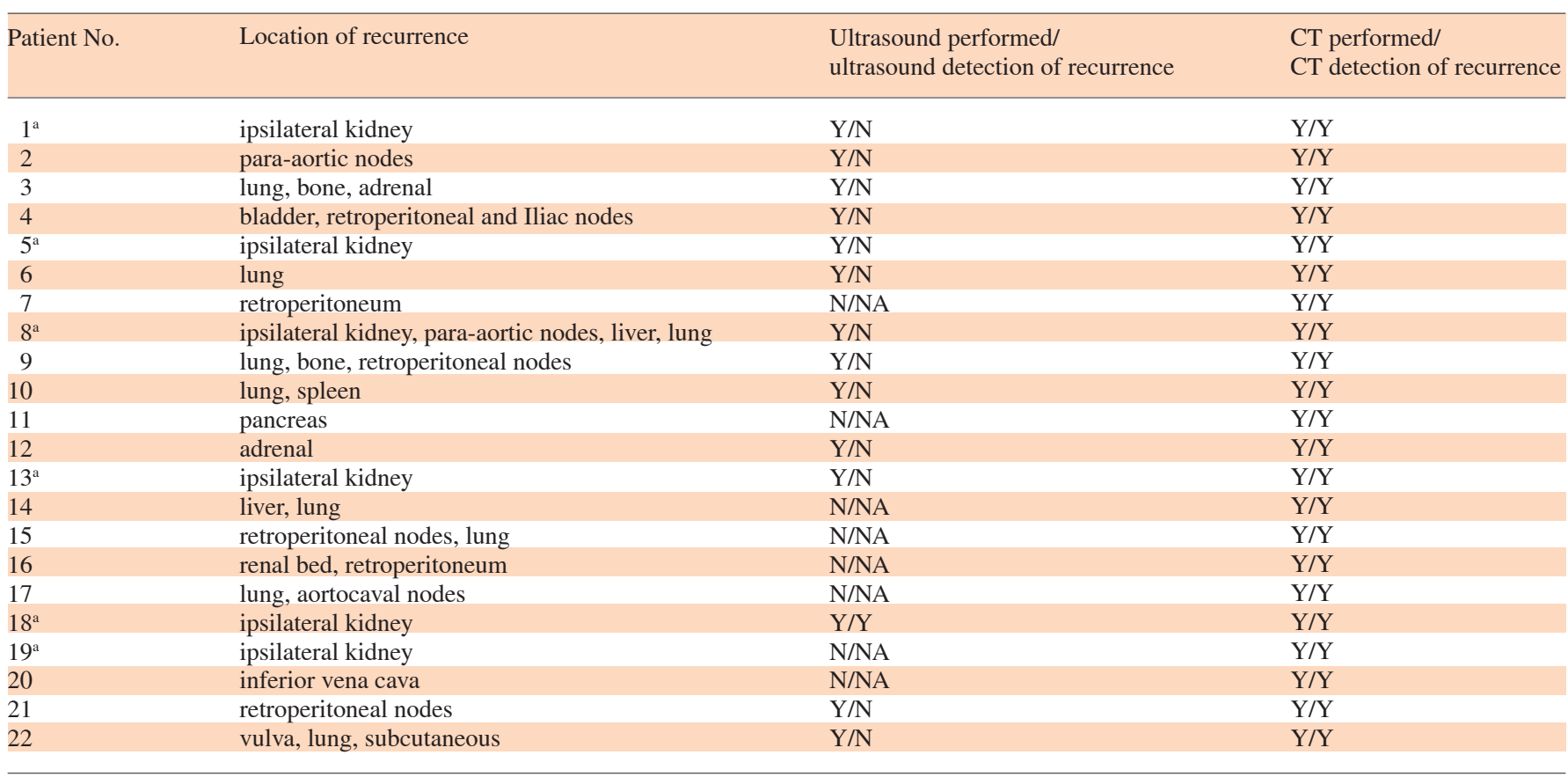

$\mathrm{Y}=$ Yes; $\mathrm{N}=$ no; $\mathrm{NA}=$ not applicable. ${ }^{\mathrm{a} C o r r e s p o n d s}$ to patients who underwent PN at initial surgery.

and 3 and duration to disease recurrence is demonstrated in table 3. Histological subtype included clear cell $(\mathrm{n}=$ $18)$, papillary $(n=2)$, acquired cystic $(n=1)$ and mixed clear cell/papillary $(n=1)$. Fifteen tumors were $\geq$ Fuhrman Grade 3 and 7 were Fuhrman Grade 2. Eleven of 16 RNs where recurrence was later identified had negative surgical margins; one of the 6 PNs had a positive margin. Ten tumors were $\leq \mathrm{pT} 2$ and 12 were $\mathrm{pT} 3$.

\section{Recurrent RCC}

Median duration to RCC recurrence was 28.5 months (range 2-66 months) (table 3). Fourteen patients (64\%) underwent ultrasound during their follow-up surveillance protocol and 1 case of disease recurrence was detected by ultrasound before subsequent confirmation with CT. All 22 patients underwent CT as part of their follow-up surveillance protocol and all recurrences were detected by this modality. The median interval from the most recent ultrasound to the index, diagnostic $\mathrm{CT}$ for recurrent RCC was 6 months (range 1-22 months). Sites of recurrent RCC and patient specific follow-up protocols with ultrasound and/or CT are demonstrated in table 4. Sites for recurrent RCC included the ipsilateral kidney, lung, retroperitoneum, bone, adrenal gland, spleen, bladder, iliac lymph nodes, pancreas, inferior vena cava, liver, vulva and subcutaneous tissue (table 4). Of the 6 patients who had recurrence in their ipsilateral kidney after PN, five had undergone ultrasound in their surveillance protocol and this modality failed to detect a recurrence in four of these patients.

\section{Discussion}

Prompt diagnosis of local and contralateral kidney recurrence is crucial since the most effective treatment is surgical resection [12-14]. Patients who undergo surgery when local recurrences become symptomatic have a higher rate of incomplete resection of recurrence, positive surgical margins and poorer survival [15]. The 5-year survival after surgery for RCC-related solitary or multiple lung metastases ranges from 24 to $60 \%$ with greater survival rates found in patients where complete surgical resection of the metastatic burden is achieved [16-19]. Similarly, Thomas et al. [20] noted that recurrence size is an independent predictor for RCC-specific death when 
treated surgically. These findings emphasize the critical importance of reliable surveillance imaging as early detection of recurrent RCC potentiates a greater array of management options for patients.

Furthermore, with the advent of targeted therapy, immune checkpoint inhibitors and the development of mini-invasive ablative therapy, along with improved surgical technology, treatment options for recurrent RCC are evolving. With this evolution, however, comes the need for accurate surveillance and early detection of recurrent lesions. As the purpose of post-operative surveillance must be the detection of curable recurrence, recommendations should consider the most appropriate imaging modalities as well as the optimal duration of surveillance [21].

RCC recurrences can develop in low-risk RCC patients with recurrence rates ranging $0-7 \%$ in pT1 tumors and $5.3-26.5 \%$ in pT2 tumors patients; recurrence rates for Fuhrman Grade 1 tumors are approximately $9 \%$ and up to $61 \%$ for Fuhrman Grade 2 tumors [22-29]. In our study, all 5 recurrences for pT1 tumors were after PNs and in the same kidney. Four of these patients had ultrasound in their follow-up schedules - in 3 cases, ultrasound failed to identify a tumor recurrence. Interestingly, only one of these 5 patients had a positive surgical margin - this finding emphasizes that recurrences are not uncommon even in those least expected to have such, highlighting the importance of sensitive imaging.

AUA and NCCN guidelines will not detect approximately one-third of all recurrences when strictly followed [30]. One review of 3,651 patients treated with surgery for RCC noted that the current $\mathrm{NCCN}$ and AUA guidelines do not detect $60 \%$ of recurrences of pT1 disease [30]. Notably, ultrasound is included in both follow-up schedules (table 1). Stratification criteria for "low risk", "intermediate risk" and "high risk" categories for RCC follow-up purposes vary among consensus guidelines. Traditionally, it has appeared reasonable to classify Fuhrman Grade $\leq 2$ and $\mathrm{pT} \leq 2$ as either 'low' or 'intermediate' risk and both categories include surveillance ultrasound among consensus guidelines. In our study, 7 patients with recurrent RCC had Fuhrman Grade 2 disease and 10 patients had $\mathrm{pT} \leq 2$ disease on histopathology. Worryingly, the CAU advise that ultrasound is sufficient in pT1 and pT2 disease for detecting abdominal recurrences and suggest that annual follow-up is sufficient after 12 months post-operatively [11]. It is interesting to note that in our cohort, the median time between the last ultrasound and the index CT which ultimately diagnosed disease recurrence was just 6 months, confirming that patients were imaged on a very timely basis.
At present, there are no available serum or urine biomarkers for detecting recurrent RCC and imaging remains the gold standard diagnostic modality. About $50-60 \%$ of recurrences occur in the lungs and it has been demonstrated that chest X-ray has a low diagnostic yield for surveillance after nephrectomy for pT1-3N0M0 RCC [31]. Though the main focus of our study was on the diagnostic role of ultrasound in follow-up protocols rather than chest X-ray, it's informative to note that there were 9 patients in our cohort with lung metastases - seven of these also had concomitant intra-abdominal metastases. While ultrasound would not be expected to pick up lung metastases, its role is to detect findings in the abdomen which seemingly coexist very frequently. In our study, 4 of these 7 patients did have abdominal ultrasound surveillance and no recurrences were diagnosed by this modality. This raises concerns about the popular combination of ultrasound and chest X-ray in RCC follow-up. Likewise, ultrasound will not be useful for identifying suspected metastatic disease in the brain, head and neck and so CT (or MRI) should always be used in such instances.

There is a lack of data on the performance of ultrasound for detecting abnormal lesions in the adrenal glands, spleen and retroperitoneal lymph nodes. One study demonstrated that normal adrenal glands can be visualized by ultrasound in $80 \%$ of cases; however difficulties frequently occur as the echogenicity of adrenal tissue is similar to retroperitoneal fat [32]. Other confounding factors with ultrasound are the acoustic window, quality of equipment and examiner experience. Regarding the detection of lymph nodes, ultrasound has recently been shown to have low sensitivity in assessing the retroperitoneal compartment in a large study of metastatic ovarian cancer [33]. Similarly, it has been reported that ultrasound will fail to identify one third of splenic metastases [34].

In the present study, 6 patients had recurrence in the ipsilateral kidney after undergoing PN of whom five underwent ultrasound during surveillance. Ultrasound failed to detect a recurrence in 4 cases. The median duration from ultrasound to the index, diagnostic $\mathrm{CT}$ for recurrent RCC in this specific cohort of patients was 3 months (data not shown). This short time interval undoubtedly questions the capacity of ultrasound to discriminate between normal post-operative surgical findings and tumor recurrence in PN patients. Mouracade et al. [21] found that abdominal ultrasound detected $3.4 \%$ of abdominal recurrences in asymptomatic patients after PN. They concluded by suggesting that abdominal ultra- 
sound has low utility for detecting recurrent RCC and should have limited use for surveillance after PN. Recurrence after PN is thankfully rare, but early diagnosis is useful as the most effective treatment remains surgery $[14,35]$. Interestingly, thermoablative techniques are also increasingly used as curative therapies for clinical T1 RCC [36]. Local recurrences after thermoablation are relatively common and can be re-treated with thermoablative techniques [36, 37]. Given the disappointing performance of ultrasound following PN, we also question whether ultrasound should be included in surveillance strategies post-thermoablation.

The main finding of the present study is that ultrasound is severely limited for detecting recurrent RCC and that ultrasound seems to perform especially poorly in PN patients. We believe that CT should be the imaging of choice, except, of course, when it is contra-indicated (e.g. pregnancy, contrast allergy, chronic kidney disease). Concerns regarding radiation exposure in this setting are merited. However, it must be remembered that this factor only encompasses one aspect of the decisionmaking process for surveillance after surgery for RCC. As clinicians, it is incumbent upon us to balance patient concerns and medicolegal implications regarding failure to promptly detect recurrent RCC versus the risk of excessive radiation exposure.

Our study has limitations in that it is retrospective of a relatively small patient cohort, though we are unaware of any similar study with a bigger cohort. Secondly, not all patients in our study underwent ultrasound during surveillance as protocols were tailored to be patient specific. Thirdly, patients undergoing both ultrasound and CT follow-up had a median duration of 6 months between their last ultrasound and diagnostic/confirmatory CT for recurrent RCC. It is feasible, although highly unlikely, that recurrences developed in this intervening period and that ultrasound in fact did not "miss" these lesions. In future, a prospective, blinded study is required with patients undergoing simultaneous ultrasound and CT during every surveillance timepoint to definitively compare both imaging modalities for detecting disease recurrence.

In conclusion, recurrent RCC is associated with significant mortality and thus accurate follow-up imaging is vital for prompt diagnosis of local or distant recurrences as early diagnosis facilitates a greater array of treatment options. Our study demonstrates that ultrasound is inferior for detecting recurrent $\mathrm{RCC}$ and that $\mathrm{CT}$ should now be considered as the standard diagnostic modality during follow-up.

\section{Acknowledgement}

M.R.Q. is in receipt of a Royal College of Surgeons in Ireland Ethicon Foundation travel grant.

\section{References}

1 Tyson MD, Chang SS: Optimal surveillance strategies after surgery for renal cell carcinoma. J Natl Compr Canc Netw 2017;15: 835-840.

2 Maldazys JD, deKernion JB: Prognostic factors in metastatic renal carcinoma. J Urol 1986;136:376-379.

-3 Negrier S, Escudier B, Gomez F, Douillard JY, Ravaud A, Chevreau C, Buclon M, Pérol D, Lasset C: Prognostic factors of survival and rapid progression in 782 patients with metastatic renal carcinomas treated by cytokines: a report from the Groupe Francais d'Immunotherapie. Ann Oncol 2002;13:14601468.
4 Leibovich BC, Blute ML, Cheville JC, Lohse CM, Frank I, Kwon ED, Weaver AL, Parker AS, Zincke H: Prediction of progression after radical nephrectomy for patients with clear cell renal cell carcinoma: a stratification tool for prospective clinical trials. Cancer 2003; 97:1663-1671.

5 Cindolo L, Patard JJ, Chiodini P, Schips L, Ficarra V, Tostain J, de La Taille A, Altieri V, Lobel B, Zigeuner RE, Artibani W, Guillé F, Abbou CC, Salzano L, Gallo C: Comparison of predictive accuracy of four prognostic models for nonmetastatic renal cell carcinoma after nephrectomy: a multicenter European study. Cancer 2005;104:1362-1371.
6 Eggener SE, Yossepowitch O, Pettus JA, Snyder ME, Motzer RJ, Russo P: Renal cell carcinoma recurrence after nephrectomy for localized disease: predicting survival from time of recurrence. J Clin Oncol 2006;24:31013106.

7 Richstone L, Scherr DS, Reuter VR, Snyder ME, Rabbani F, Kattan MW, Russo P: Multifocal renal cortical tumors: frequency, associated clinicopathological features and impact on survival. J Urol 2004;171:615-620.

8 Available from: http://uroweb.org/guideline/ renal-cell-carcinoma/\#8.

9 Available from: http://www.auanet.org/ guidelines/follow-up-for-clinically-localized-renal-neoplasms-(2013). 
10 Available from: https://www.tri-kobe.org/ nccn/guideline/urological/english/kidney. pdf.

11 Available from: https://www.kidneycancercanada.ca/media/files/69.pdf.

-12 Bani-Hani AH, Leibovich BC, Lohse CM, Cheville JC, Zincke H, Blute ML: Associations with contralateral recurrence following nephrectomy for renal cell carcinoma using a cohort of 2,352 patients. J Urol 2005; 173:391-394.

13 Itano NB, Blute ML, Spotts B, Zincke H: Outcome of isolated renal cell carcinoma fossa recurrence after nephrectomy. J Urol 2000;164:322-325.

14 Sandhu SS, Symes A, A'Hern R, Sohaib SA, Eisen T, Gore M, Christmas TJ: Surgical excision of isolated renal-bed recurrence after radical nephrectomy for renal cell carcinoma. BJU Int 2005;95:522-525.

15 Levy DA, Swanson DA, Slaton JW, Ellerhorst J, Dinney CP: Timely delivery of biological therapy after cytoreductive nephrectomy in carefully selected patients with metastatic renal cell carcinoma. J Urol 1998;159:11681173.

16 Sackett DL, Rosenberg WM, Gray JA, Haynes RB, Richardson WS: Evidence-based medicine: what it is and what it isn't. BMJ 1996;312:71-72.

17 Piltz S, Meimarakis G, Wichmann MW, Hatz R, Schildberg FW, Fuerst H: Long-term results after pulmonary resection of renal cell carcinoma metastases. Ann Thorac Surg 2002;73:1082-1087.

18 Hofmann HS, Neef H, Krohe K, Andreev P, Silber RE: Prognostic factors and survival after pulmonary resection of metastatic renal cell carcinoma. Eur Urol 2005;48:77-81.

-19 Murthy SC, Kim K, Rice TW, Rajeswaran J, Bukowski R, DeCamp MM, Blackstone EH: Can we predict long-term survival after pulmonary metastasectomy for renal cell carcinoma? Ann Thorac Surg 2005;79:996-1003.
20 Thomas AZ, Adibi M, Borregales LD, Hoang LN, Tamboli P, Jonasch E, Tannir NM, Matin SF, Wood CG, Karam JA: Surgical management of local retroperitoneal recurrence of renal cell carcinoma after radical nephrectomy. J Urol 2015;194:316-322.

21 Mouracade P, Chavali JS, Kara O, Dagenais J, Maurice MJ, Nelson RJ, Rini BI, Kaouk JH: Imaging strategy and outcome following partial nephrectomy. Urol Oncol 2017;35:660. e1-660.e8.

22 Sandock DS, Seftel AD, Resnick MI: A new protocol for the followup of renal cell carcinoma based on pathological stage. J Urol 1995; 154:28-31.

23 Hafez KS, Novick AC, Campbell SC: Patterns of tumor recurrence and guidelines for followup after nephron sparing surgery for sporadic renal cell carcinoma. J Urol 1997; 157:2067-2070.

24 Levy DA, Slaton JW, Swanson DA, Dinney CP: Stage specific guidelines for surveillance after radical nephrectomy for local renal cell carcinoma. J Urol 1998;159:1163-1167.

25 Ljungberg B, Alamdari FI, Rasmuson T, Roos G: Follow-up guidelines for nonmetastatic renal cell carcinoma based on the occurrence of metastases after radical nephrectomy. BJU Int 1999;84:405-411.

26 Stephenson AJ, Chetner MP, Rourke K, Gleave ME, Signaevsky M, Palmer B, Kuan J, Brock GB, Tanguay S: Guidelines for the surveillance of localized renal cell carcinoma based on the patterns of relapse after nephrectomy. J Urol 2004;172:58-62.

27 Gofrit ON, Shapiro A, Kovalski N, Landau EH, Shenfeld OZ, Pode D: Renal cell carcinoma: evaluation of the 1997 TNM system and recommendations for follow-up after surgery. Eur Urol 2001;39:669-675.

28 Fuhrman SA, Lasky LC, Limas C: Prognostic significance of morphologic parameters in renal cell carcinoma. Am J Surg Pathol 1982;6: 655-663.
29 Lerner SE, Hawkins CA, Blute ML, Grabner A, Wollan PC, Eickholt JT, Zincke H: Disease outcome in patients with low stage renal cell carcinoma treated with nephron sparing or radical surgery. J Urol 1996;155:1868-1873.

30 Stewart SB, Thompson RH, Psutka SP Cheville JC, Lohse CM, Boorjian SA, Leibovich BC: Evaluation of the National Comprehensive Cancer Network and American Urological Association renal cell carcinoma surveillance guidelines. J Clin Oncol 2014; 32:4059-4065.

-31 Doornweerd BH, de Jong IJ, Bergman LM, Ananias HJ: Chest X-ray in the follow-up of renal cell carcinoma. World J Urol 2014;32: 1015-1019.

32 Dietrich CF, Wehrmann T, Hoffmann C, Herrmann G, Caspary WF, Seifert H: Detection of the adrenal glands by endoscopic or transabdominal ultrasound. Endoscopy 1997; 29:859-864.

- 33 Fischerova D, Zikan M, Semeradova I, Slama J, Kocian R, Dundr P, Nemejcova K, Burgetova A, Dusek L, Cibula D: Ultrasound in preoperative assessment of pelvic and abdominal spread in patients with ovarian cancer: a prospective study. Ultrasound Obstet Gynecol 2017;49:263-274.

34 Caremani M, Occhini U, Caremani A, Tacconi D, Lapini L, Accorsi A, Mazzarelli C: Focal splenic lesions: US findings. J Ultrasound 2013;16:65-74.

- 35 Bruno JJ 2nd, Snyder ME, Motzer RJ, Russo P: Renal cell carcinoma local recurrences: impact of surgical treatment and concomitant metastasis on survival. BJU Int 2006;97:933938

36 Klatte T, Grubmüller B, Waldert M, Weibl P, Remzi M: Laparoscopic cryoablation versus partial nephrectomy for the treatment of small renal masses: systematic review and cumulative analysis of observational studies. Eur Urol 2011;60:435-443.

37 Kunkle DA, Egleston BL, Uzzo RG: Excise, ablate or observe: the small renal mass dilemma-a meta-analysis and review. J Urol 2008; 179:1227-1233. 